\title{
Research and Reflection on the Construction of Virtual Simulation Experiment Teaching Center of Bioengineering in the Background of Excellence Program
}

\author{
Lili Guan ${ }^{1,}$, Linna Du, b, Songlei Guan ${ }^{1, c}$, Peng Han ${ }^{1, d}$, Xiyan Cui ${ }^{1, e}$, Hao \\ Dong ${ }^{1,}$ and Linbo Zhang ${ }^{1 g^{*}}$
}

${ }^{1}$ College of Life Science, Jilin Agricultural University, Changchun 130118, China

a32233603@qq.com, b511830071@qq.com, ${ }^{c} 17736856 @ q q . c o m,{ }^{d} 17736856 @ q q . c o m$

ef174655675@qq.com, ${ }^{\mathrm{f}}$ donghao_jlau@qq.com, ${ }^{9} \mathrm{cczlb} @ 126 . c o m$

Corresponding author: Zhang Linbo, male, professor

Keywords: Excellence program; Virtual simulation; Experimental teaching; Innovation

\begin{abstract}
This paper discusses the background, necessity and thoughts of constructing virtual simulation teaching experiment teaching center in view of the existing problems in the practice of teaching bio-agriculture and combined with the training objectives of the "Top-Notch Innovative Agriculture and Forestry Talents Training Model Reform Project". The integration of the practice of agricultural science is of great significance to improve the students' professional accomplishment and innovation ability and promote the teaching reform.
\end{abstract}

\section{Background of Proposing the Construction of Professional Virtual Simulation Experiment Center}

"Excellent Engineering Education and Training Program" ("Excellence Program" in short) is a major reform program for the National Ministry of Education to implement the "National Medium and Long-Term Educational Reform and Development Plan (2010-2010)" and "Outline of National Medium and Long-Term Talent Development (2010-2020)" and also a major measure to promote China develop from a big engineering and education country to an engineering and education giant, aiming at cultivating a large number of various types of high-quality engineering and technical talents with strong innovation ability and can adapt the economic and social development.

Relying on the experimental teaching demonstration center of colleges and universities to carry out virtual simulation teaching is an important measure for colleges and universities in China to implement experimental teaching reform in recent years [1]. Under the guidance of teachers, activities and projects related to agronomic biology are carried out, and for experiments with long cycle, great danger and high cost, teachers and students are encouraged to jointly develop virtual simulation projects and establish highly simulated virtual experimental environment and experimental objects through multimedia, data and network communication registration book to achieve the teaching effects of the teaching program. [2]

\section{Necessity of Constructing Virtual Simulation Experiment Teaching Center of Biology}

Requirement of National Educational Reform and Development Direction. In August 2013, it was clearly pointed out in the "Notice on Constructing National Virtual Simulation Experimental Teaching Center" of the Ministry of Education that virtual simulation experiment teaching is an important content in higher education information construction and the construction of teaching demonstration center, and it is the product of the deep integration of subjects and majors with information technology. The construction of virtual simulation experiment teaching center adheres to the guiding ideology of "scientific planning, sharing resources, highlighting key points, 
improving efficiency and sustainable development", aiming at comprehensively improving the innovative spirit and practical ability of college students and taking high-quality experimental teaching resources at the core. Build a number of demonstrating and leading virtual simulation experimental teaching centers, and continue to promote the construction of experimental teaching information as well as the reform and innovation of experimental teaching at colleges and universities. Construction of virtual simulation experiment teaching centers includes: management and sharing platform of virtual simulation experiment teaching resources and virtual simulation experiment teaching, virtual simulation experiment teaching and management team, virtual simulation experiment teaching center management system [3].

Requirement of the School's overall Construction and Development Goals. The existing experimental teaching resources and conditions of the College of Biosciences have been unable to match the training and requirements of first-class undergraduate and postgraduate talents. It is necessary to strengthen the construction of biological agriculture laboratory, enrich the teaching and research resources, improve the biological agriculture teaching, scientific research infrastructure and other school conditions, open and share teaching and research researches to provide strong guarantee for cultivating high-quality application, research and compound talents and scientific innovation.

Modern Agricultural Enterprises' Demand for Talents. With the rise of modern service industry and modern agriculture, increasing importance is attached to the agricultural enterprise management information and resource integration, and modern agricultural enterprises' demand for talents is no longer limited to operational talents with single skills, but they prefer high-quality comprehensive talents who can combine theoretical knowledge and professional theories with profound understanding of business, application ability, efficient work methods and thinking modes and can also master various basic skills and mainstream tools. They take cultivating business backbones and low-and-medium-level business managers as the goals as well as compound and innovative professional talents who understand the enterprises' internal management and external environment and meet the enterprises' demands in management, communication, assistance and decision-making. The difference between enterprises changed demands and the old talent cultivation mode at colleges and universities has raised higher requirements for the teaching system and talent cultivation mode of bio-agriculture colleges.

Requirements for the Development of Experimental Teaching of Biological Agriculture. The 21 st century is the century of biology. For nearly a decade, the rapid development of engineering technology has greatly changed the appearance of traditional agriculture. The biological science and agricultural science are closely overlapped and integrated and it has become an inevitable trend for the future development of agriculture to use modern life science to transform traditional agriculture so as to create bio-agriculture. Bio-agriculture seeks to manage agriculture in accordance with natural biology processes, invest in energy and resources, and maintain the system's best productivity. Bio-agriculture emphasizes the conservation of pests and diseases by promoting biological processes and biological cycling, and the biological balance of the agricultural environment. In the process of the development of bio-agriculture industry in urgent need of a large number of modern advanced life science concept, master the modern agricultural science and technology of advanced application-oriented professionals, so the higher agricultural engineering and engineering personnel training system and supporting facilities is particularly important. In the process of training the bio-agricultural personnel by the venue, equipment, equipment, hours and other effects, some experimental content cannot be effectively carried out, restricting the improvement of teaching quality. The establishment of virtual simulation practice teaching platform 
can effectively solve some of the high-input, high-risk practice projects for equipment and environmental requirements, to better simulate the production processes and processes, build a combination of theory and application of communication platform to improve the relevant practice courses of the teaching effect, help to improve the quality of engineering and related professional personnel training [4].

Help to Improve Students' Quality and Cultivate High-Quality Application, Research and Compound Talents. Experimental teaching is an effective way to improve students' practical ability and innovation ability. The management laboratory should be an important base for cultivating students' practical ability and innovation ability of bio-agriculture. Therefore, it is important to strengthen the experimental teaching of bio-agriculture in our university, strengthen the practice education, reform the experimental teaching system and mechanism of bio-agriculture, and improve the cultivation ability of bio-agriculture students and improve the level of personnel training's value.

Build into a First-Class National Virtual Simulation Experimental Teaching Center. The cloud technology is applied to the plan of constructing bio-agriculture laboratory to establish a platform integrating resource sharing, independent learning, experiment teaching, training practice and scientific research combined with elements of simulation practice scene, teaching laboratory and virtual simulation experiment teaching platform so as to combine vitality and reality and make them complement with each other. The project is based on the foundation of the provincial bio-agriculture experimental teacher center and in accordance with the national level of experimental teaching demonstration as the construction standards. Carry out unified planning in accordance with the guiding thoughts and construction requirements of national virtual simulation experimental teaching center to build a first-class national experimental demonstration center.

Realize Resource Sharing and Absorb Off-Campus Resources to Improve Economic and Social Benefits. Virtual simulation experiment teaching management and sharing platform can achieve a high degree of sharing teaching and research resources and expand the experimental teaching from the originally machine room to any places at campus at any time to maximize the usage of teaching resources. Meanwhile, strengthen effectively management of laboratories, effectively improve the security of information, reduce management cost, hardware cost and repeated construction of resources to improve the utility rate of equipment and resources. The laboratory will adhere to the principle of opening up and make full use of the construction opportunity of the demonstration center of bio-agriculture experiment to meet the needs of high-quality personnel training, deepen communication and docking with enterprises, expand the channels of cooperation between schools and enterprises, and obtain more economic and social benefits.

\section{Thoughts on the Construction of Virtual Simulation Experiment Teaching Center of Bio - agriculture Specialty}

The construction of the virtual simulation experiment teaching center of bioengineering is to make full use of and integrate the existing experimental teaching resources, teachers' resources and network infrastructure resources from the actual needs of the current undergraduate and postgraduate courses in the school. Implement virtual simulation experiment teaching center to provide an open, design and innovative teaching and research environment for students and teachers at any time and any place through the campus network. After conditions become mature, it can be opened to teachers and students all over the school and realize resource sharing.

Innovative Experimental Teaching Module of Virtual Experiment of Biological Agriculture. 
(1) "Four - Level and Four - Combination" Virtual Simulation Teaching System.In accordance with the principle of "strengthening the foundation, improving the ability and comprehensive cultivation", the " $4+4$ " mode is formed, that is, start from cultivating students' practical ability and innovation awareness to set personalized and innovative virtual simulation experiment projects, strengthen training of students' professional skills, cultivate their comprehensive design ability and innovation ability so as to construct a step-by-step "four-level and four-combination" virtual simulation teaching system. The four-level refers to professional basic experiments, professional skills experiments, comprehensive design and simulation training and innovation practical activities to realize "leveled cultivation, progressive and gradual improvement" through four levels and finally achieve the requirements of teaching goals through "four-combination" in practical implementation. The four-combination refers to: combination of theoretical courses and virtual simulation experiment course: virtual simulation experiment corresponds with the subject platform courses and professional core courses of each major. Besides, in the teaching plan, there is systematic arrangement of the teaching time of theoretical courses and virtual simulation experiment courses so that after mastering certain theoretical knowledge, students can have an intuitive understanding of the application field and methods of virtual simulation experiments, thus enhancing students' interest in learning and the ability to master and apply knowledge. The combination of physical experiment with virtual simulation experiment: virtual simulation experiment focuses on the long-term evolution of communication systems and extreme events such as that the physical experiment cannot be carried out, and it complements with physical experiment. Combination of on-campus experiments and off-campus exchanges/practices: the communication and information system problems shown by virtual simulation experiments often have a profound realistic background. The school arranges students to take off-campus internship, visit training base and take other practices to further enhance the combination of vitality and reality to promote students combine theories and reality. Combination of virtual simulation experiment teaching with scientific research: the center provides students with extra-curricular comprehensive design and virtual simulation experimental projects so that students can freely choose the topics and carry out innovative research works through the center's virtual simulation experiment platform under the guidance of teachers.

(2) Exploration and Application of Virtual Simulation Teaching Based on Case Teaching Method and Mode.Courses of agronomy biology are highly practical and comprehensive with a lot of application technologies, so it is difficult for students to understand and master relevant theoretical knowledge at the limited class hours, and it can also weaken students' enthusiasm in study. Therefore, to deeply understand students' dominant positions in teaching activities, fully utilize multimedia teaching methods and select contents closely related to agricultural production technologies and combine virtual simulation experiment to provide students with the opportunities to study and carry out practical operation through cases. Students can apply theoretical knowledge in practice, and also, through case teaching, theoretical knowledge is imparted to students to be well connected with practical teaching to help students understand and consolidate the learned theoretical knowledge and arouse their interest in study.

(3) Exploration and Application of Virtual Simulation Teaching Based on MOOC.The concept of Massive Open On-Line Course (MOOC) was first proposed by Professor Dave Cormier and Bryan Alexander in 2008. The MOOC can be easily used with low cost (most of it is free of charge), covers a wide range of people and support independent learning with rich learning resources, so it develops rapidly and exerts huge impact on higher education [5]. At present, MOOC has already become an important integral part of China's national boutique open course construction project 
and is the important force promoting the construction of virtual simulation key laboratory of China [6]. The significance of constructing MOOC-based agriculture virtual simulation laboratory center lies in that it uses Internet technologies and cloud open education platform to share high-quality resources of higher education with great significance on promoting the reform of agricultural biology of higher education, innovating education and teaching mode, promoting communication and cooperation between colleges and enterprises, expanding colleges' social influence, improving teachers' social publicity as well as the quality of innovative agriculture and forestry talents [7-8].

(4)Organic Combination of Production Practice and Virtual Simulation Experiment Teaching.Organize students to participate in animal breeding, veterinary drug preparation, testing, sales and other production activities and introduce them into the teaching of relevant knowledge, striving to synchronize virtual simulation experiment teaching with teaching of theories as far as possible, which is conducive for students to understand the theoretical knowledge. Besides, timely carry out agricultural production activities to promote students understand and mastery of knowledge point, improve students' enthusiasm in learning, consolidate their theoretical knowledge so as to master practical technology of agricultural production.

The Construction of Virtual Simulation Experiment Center of Agricultural Biology Promotes the Reform of Experimental Teaching.In the established virtual simulation practice teaching project, students can independently master the time of practical operation, complete summary, evaluation and assessment of the practical environment, practical process simulation, man-machine interface and practice results in virtual simulation practical teaching, and use flexible operation and interaction to guide practice; and teachers mainly plan the teaching contents, monitor students' learning process, allocate learning resources and evaluate students' learning effects[9]. Practical teaching is no longer limited to tangible practice, but the time and space of animal breeding, disease diagnosis and management have been expanded and extended to provide students with a moveable virtual teaching site for training thus improving teaching quality and counseling efficiency.

The construction of virtual simulation experiment teaching adheres to the concept of "combining vitality and reality, mutual complementary, strive to be real" with "reality" as the goal and "vitality" as the means to enhance advantages and avoid disadvantages. "Vitality" is used to strengthen the link between theoretical knowledge and actual operation, and "reality" is used to improve students' ability to solve practical problems. Virtual experimental means are integrated into pre-class preview, class training and after-school practice to improve students' comprehensive ability to the maximum degree. During the process of developing virtual simulation experiment teaching system, the virtual simulation center adheres to the basic thought of "key development, active introduction and appropriate advancement" to give priority to the experimental projects with strong professional theoretical knowledge to develop pilot of virtual system. Meanwhile, active introduce mature virtual experiment teaching system from abroad and pay full attention to the reality and operation of virtual experiment environment. Adopt the "multi-layer" open mode for students[10]. Combine the opening of experiment site and time with laboratory website, which includes three parts: infinite opening of virtual experiments, reserved opening of teaching laboratories (regular opening and booked opening of websites) and opening of innovation base to maximize the use of existing resources and promote the cultivation of innovative ability. The built-in virtual simulation project can be viewed on campus and through campus network.

\section{Acknowledgements}

This research was supported by scientific research program of Jilin Association for Higher Education (Grant No.JGJX2016D32). 


\section{References}

[1] Q Liu, W.C Zhang, T.C Long and X.L Wang, Current Situation and Thinking on the Construction of National Biomedical Virtual Simulation Experiment Center, China Medical Education Technology, Vol.31(2017) No.1,p. 15-18. (In Chinese)

[2] Y Yang, Y Wu, S.M Ye. Exploration of Lin Xueqiu Virtual Simulation Experiment Teaching for the Cultivation of "Excellence in Agriculture and Forestry Engineer", New Curriculum Research, Vol.12 (2016), p. 56-58. (In Chinese)

[3] B.C Zhou, J.H Huang. Establish Virtual Chemistry Laboratory and Further Open the Laboratory, Experiment Platform, Vol.1(2013),p. 248-249. (In Chinese)

[4] X.F Shi, Y.X Yuan. Current Status and Future Development of Mobile Learning in Higher education ,China Education Network, Vol.4(2015),p. 35-38. (In Chinese)

[5] W.L Wang. The Development of MOOC and Its Influence on Higher Education, Jiangsu Higher Education, Vol.2 (2013), p. 53-57. (In Chinese)

[6] P Huang, H.S Li, K.J Pan and X Zhang, Discussion on the Construction of Medical Virtual Simulation Laboratory Based on MOOC, Experimental Technology and Management, Vol.31 (2014) No.12, p. 104-106. (In Chinese)

[7] 2013 MOOCs White Paper Phase I, China Education Network. http: //www.edu.cn/html/rd/

[8] MOOC1/

[9] 2013 MOOCs White Paper Phase II, China Education Network. http: //www.edu.cn/html/rd/

\section{[10] MOOC2/}

[11]F Liu, P.J Mo, C.L Liang, Application of Virtual Simulation Technology to Construct Practical Teaching Links in Higher Vocational Education ,Popular Technology, Vol.10(2014),p. 149-151. (In Chinese)

[12] Li P, Mao CJ, Xu J. Construction of the national virtual simulation experiment teaching centers, improving the experimental teaching informatization in higher education[J].Research and Exploration in Laboratory, Vol.32(2013) No.11,p. 5-8. 